\title{
Eyebrows raised over extended age range for cervical cancer vaccine
}

At the high-profile meeting of the American Society of Clinical Oncology in June, the pharmaceutical giant GlaxoSmithKline (GSK) made a carefully timed presentation. The company showed data demonstrating that Cervarix, its cervical cancer vaccine, "is highly immunogenic and well tolerated in women over 25 years of age."

The company said the results suggest that the vaccine could benefit all women, regardless of age.

Three days later, Merck announced that it had won the first, coveted approval of the US

\section{Mobile clinic model debuts in Manhattan}

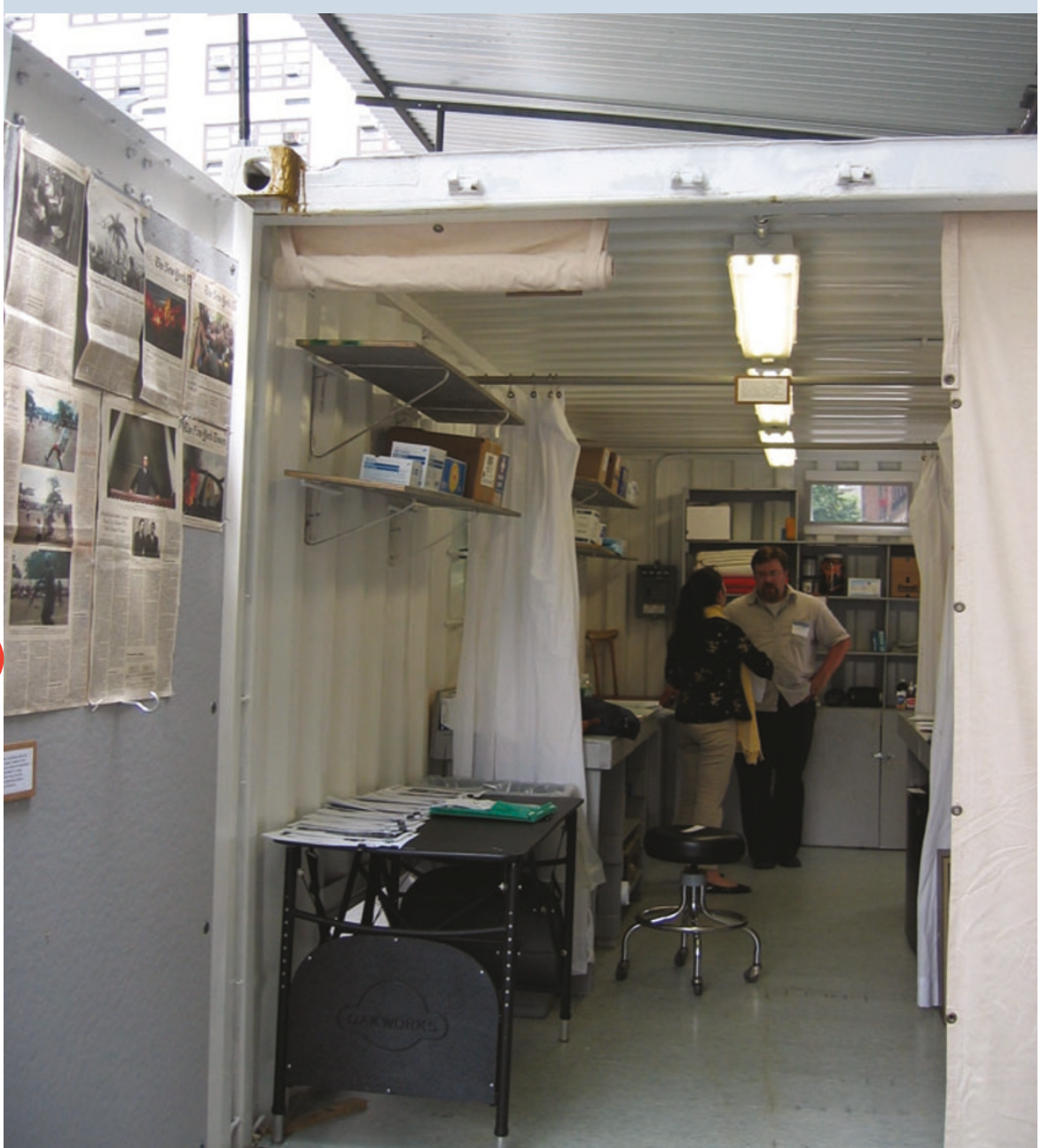

Retrofitted from an 8-by-20 freight shipping container, Rx Box is a prototype mobile health clinic that promises to treat people in the poorest villages of the world. The Council on Foreign Relations and the Rensselaer Polytechnic Institute, which together developed Rx Box, unveiled the clinic in New York City on 14 June. The solar-powered Doc-in-a-box is designed to be staffed by one medic and offer 1,800 people each year primary care and screening for HIV/AIDS, hepatitis, tuberculosis and malaria. The prototype cost $\$ 4,000$ to build, but the council estimates that mass production could cut that price by half.
Schiller of the US National Cancer Institute, whose group made the scientific discovery on which the vaccines are based (Proc. Natl. Acad. Sci. USA 89, 12180-12184; 1992). “It's quite clear that there is a law of diminishing returns."

Merck's Gardasil is only effective in women who haven't previously been infected with two leading cancer-causing strains of the common sexually transmitted human papilloma virus, together estimated to cause $71 \%$ of cervical cancers (Int. J. Cancer 111 , $278-285 ; 2004)$. But because blood tests for prior exposure are unreliable, investigators have used age as a proxy for sexual activity.

Both Merck and GSK are pressing ahead with trials aimed at showing the vaccine is effective in women between the ages of 26 and 45 or 55 . There's a clear commercial incentive involved: at $\$ 360$ for a three-dose course, the Merck vaccine has the potential to generate more revenue for its maker than any other vaccine in history. GSK is likely to price its vaccine similarly.

Gary Dubin, GSK's global chief of cervical cancer vaccine development, argues that, regardless of sexual exposure, the vaccine could benefit older women. "I don't think there's any magic cutoff when women are no longer at risk for HPV infection," he says. "You can't say 25 is a cutoff."

The GSK vaccine targets the four most dangerous strains, collectively estimated to cause $80 \%$ of cervical cancers. "Unless a woman has been infected with all four types, which is unlikely," he says, "she would still potentially benefit from protection."

Still, some health experts are skeptical about the vaccine's use in older women.

"I think the effort will be to find ways to pay for younger women to have access, not older women," says Arthur Caplan, director of the Center for Bioethics at the University of Pennsylvania. "It will be something [older women] pay out of pocket and a relatively small number may wind up doing this."

Ironically, the women who would most benefit from vaccination are those least likely to get it (Nat. Med. 11, 359; 2005). Cervical cancer is the leading cause of cancer deaths among women in developing countries.

"It is an enormous ethical challenge to make the vaccine available to those who need it most," notes Caplan. "Without some subsidy from somewhere or discount pricing, there is just no way they are ever going to see this vaccine."

Meredith Wadman, Washington, DC 